EGU2020-12314, updated on 26 Feb 2021

https://doi.org/10.5194/egusphere-egu2020-12314

EGU General Assembly 2020

(c) Author(s) 2021. This work is distributed under

the Creative Commons Attribution 4.0 License.

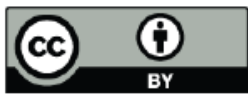

\title{
The Adams Event, a geomagnetic-driven environmental crisis 42,000 years ago
}

\author{
Alan Cooper ${ }^{1}$, Chris Turney ${ }^{2}$, and the Adams Event Team* \\ ${ }^{1}$ BlueSky Genetics, Australia (alan.cooper@blueskygenetics.com) \\ ${ }^{2}$ University New South Wales, Sydney, NSW 2052, Australia \\ ${ }^{\star}$ A full list of authors appears at the end of the abstract
}

Geological archives record multiple reversals of Earth's magnetic poles, yet the potential impacts of these events remain unknown. The lack of any obvious association between the last major inversion, the Laschamps Excursion $\sim 41$ thousand years ago (ka), and polar ice paleoclimate records has underpinned the view that geomagnetic reversals do not have major environmental consequences. We find this is not the case. Importantly, the weakened geomagnetic field causes rapid production of atmospheric radiocarbon, and the lack of accurate calibration records has complicated dating of environmental and archaeological events in other parts of the world. Here we exploit the first detailed record of radiocarbon levels across the Laschamps Excursion using New Zealand swamp kauri (Agathis australis) trees to precisely align Pacific Basin environmental changes with polar paleoclimate records (via ${ }^{10} \mathrm{Be}$ ). Comprehensive radiocarbon-dated and glacial sequences are consistent with global chemistry climate modelling, and show synchronous climate changes across the mid to low latitudes that are concentrated during the geomagnetic field minima (42.2-41.5 $\mathrm{ka}$ ) in the transitional phase that precedes the Laschamps Excursion. Critically, the revised timing reveals associations with a wide range of extinction events and major changes in the global archaeological record, which we hereby term the Adams Event. The climatic, environmental, and evolutionary impacts of past magnetic reversals now form a critical issue for future investigation.

Adams Event Team: Jonathan Palmer, Alan Hogg, Matt McGlone, Janet Wilmshurst, Andrew M. Lorrey, Timothy J. Heaton, James M. Russell, Raimund Muscheler, Florian Adolphi, Julian Anet, Anthony Dosseto, J. Tyler Faith, Pavla Fenwick, Chris Fogwill, Konrad Hughen, Mat Lipson, Ken McCracken, Norbert Nowaczyk, Thomas Peter, Eleanor Rainsley, Christopher Bronk-Ramsey, Eugene Rozanov, Paolo Sebastianelli, Yassine Souilmi, Janelle Stephenson, Ivo Suter, Zoe Thomas, Ray Tobler, Roland Zech 